\title{
SOBRE O AINDA-NÃO-CONSCIENTE: A CRÍTICA DE ERNST BLOCH AO INCONSCIENTE FREUDIANO
}

\author{
[ ABOUT THE NOT-YET-CONSCIOUS: THE CRITICISM OF ERNST BLOCH TO THE FREUDIAN \\ UNCONSCIOUS ]
}

Thiago Reis *

Universidade Federal de Ouro Preto (UFOP), Brasil

\begin{abstract}
RESUMo: Este artigo pretende investigar como Ernst Bloch delineia os fundamentos de uma nova forma de inconsciente, baseado no pensamento utópico-concreto, mediado pelos devaneios de uma mundo melhor, em contraposição à Freud e seu foco no inconsciente reprimido.
\end{abstract}

Palavras-chave: Ainda-não-consciente; Inconsciente; Marxismo; Freud
ABSTRACT: This article intends to investigate how Ernst Bloch outlines the grounds of a new form of unconscious, based in utopian-concrete thinking, mediate by the daydreams of a better world, instead Freud and his focus about a repressed unconscious.

KEYWORDS: Not-yet-conscious; Inconscious; Marxism, Freud

A reorientação do papel da filosofia, proposto a partir de Marx, esteve concomitantemente ligada a uma reorientação do pensamento e da práxis, sob a exigência efetiva da liberdade. Aos olhos de Bloch, a filosofia marxiana aparece "como aquela que finalmente se comporta de modo adequado frente ao devir e ao que está por surgir" (BLOCH, 2005, p. 19). Nesse sentido, o filósofo evidenciará a importância do futurum para o materialismo histórico, como conditio sine qua non para que haja a transformação concreta do mundo, tal como ela fora formulada por Marx em sua última tese sobre Feuerbach. Em linhas gerais, poderíamos afirmar que o materialismo histórico, de acordo com a perspectiva blochiana, é a única filosofia que se mostra capaz de perceber nas páginas ainda brancas do futuro a figura messiânica do devir, caracterizada aqui pelo novum (o radicalmente novo), pelo busca incansável da pátria autêntica. A esperança, cujos olhos sempre se voltaram para aquilo que ainda não é, ganhará aqui um espaço que jamais lhe fora concedida ao longo de toda a história da filosofia. Como observa Bloch, o princípio esperança, apesar de ter sido rejeitado por tanto tempo, é um afeto que atuou continuamente no processo de transformação do mundo. E para dar à esperança o seu lugar adequando no campo da experiência filosófica, o filósofo se servirá de alguns pressupostos que, a nosso ver, constituem uma reviravolta no próprio modo de teorizar.

* Doutor em Filosofia pela Universidade Federal de Minas Gerais (UFMG), Mestre em Estética e Filosofia da Arte pela Universidade Federal de Ouro Preto (UFOP). m@ilto: thiagoreis85@yahoo.com.br 
A reorientação do papel da filosofia, proposto a partir de Marx, esteve concomitantemente ligada a uma reorientação do pensamento e da práxis, sob a exigência efetiva da liberdade. Aos olhos de Bloch, a filosofia marxiana aparece "como aquela que finalmente se comporta de modo adequado frente ao devir e ao que está por surgir" (BLOCH, 2005, p. 19). Nesse sentido, o filósofo evidenciará a importância do futurum para o materialismo histórico, como conditio sine qua non para que haja a transformação concreta do mundo, tal como ela fora formulada por Marx em sua última tese sobre Feuerbach. Em linhas gerais, poderíamos afirmar que o materialismo histórico, de acordo com a perspectiva blochiana, é a única filosofia que se mostra capaz de perceber nas páginas ainda brancas do futuro a figura messiânica do devir, caracterizada aqui pelo novum (o radicalmente novo), pelo busca incansável da pátria autêntica. A esperança, cujos olhos sempre se voltaram para aquilo que ainda não é, ganhará aqui um espaço que jamais lhe fora concedida ao longo de toda a história da filosofia. Como observa Bloch, o princípio esperança, apesar de ter sido rejeitado por tanto tempo, é um afeto que atuou continuamente no processo de transformação do mundo. E para dar à esperança o seu lugar adequando no campo da experiência filosófica, o filósofo se servirá de alguns pressupostos que, a nosso ver, constituem uma reviravolta no próprio modo de teorizar.

$\mathrm{O}$ intento geral da filosofia do ainda-não será o de romper com o paradigma do conhecimento que se instituiu, desde Platão, na anámnesis e, a partir daí, estabelecer um novo tipo de saber, que não mais esteja amarrado à rememoração, à pura contemplação do que-já-se-efetivou, enfim, não mais resignado ante a impotência de uma filosofia que, como havia sugerido Hegel, deveria apenas lançar a sua "luz crepuscular" a um mundo já anoitecido. Ao invés do crepúsculo, Bloch comungará com a aurora. Se o futurum ainda não foi compreendido filosoficamente, isso se deu justamente porque o entendimento humano, até agora, não foi capaz de nominar e compreender essa propriedade e "reiteradamente excluía o que lhe sobrevinha". (BLOCH, 2005, p. 16). O mundo, interpretado de acordo com as categorias tradicionais da consciência, fatalmente se tornou, segundo o filósofo, um mundo da repetição, ou do grande outra vez. Em consequência disso, afirma Bicca (1987, p. 22), "para se produzir um teorizar transformante desde o início, há que se inverter o direcionamento do tempo, há muito intocado, o modo temporal reinante na gênese do trabalho intelectual".

Sob a ótica de Bloch, o pensamento dialético-materialista adquirirá novos contornos: será articulado concomitantemente a uma ontologia que tem como pressuposto fundamental a processualidade do ser: a ontologia do ainda-não. Deste modo, poderá a filosofia tomar consciência do empreendimento processual, da incessante transformação que brota no cerne da matéria de que é feito o mundo. Por esse motivo, o pensamento deverá se pautar pela exigência experimental de sua própria atividade intelectual, e voltar-se para o que ainda permanece em aberto, não só em relação ao passado, mas de modo determinante no futuro. Para tanto, Bloch tentará aclarar os aspectos fundamentais, bem como restituir a importância, dos sonhos diurnos, por serem eles possuidores uma abertura manifesta frente ao princípio de realidade, operando imagens do desejo que, em última instância, podem apontar para a superação do já-dado.

A psicanálise, nesse ínterim, se torna um contraponto referencial para a constituição mesma da antropologia blochiana. A recorrência à Freud por parte de Bloch servirá sobretudo ao propósito de criticar a tendência do pensamento ocidental que se habituou a se servir do passado: "os sonhos noturnos se nutrem da vida impulsiva que ficou para trás, de material imaginário passado, quando não arcaico, e não acontece nada de novo sob o clarão de sua lua descoberta" (BLOCH, 2005, p. 89). 
Isso não quer dizer que, para Bloch, a interpretação psicanalítica dos sonhos não possua a sua relevância clínica; todavia, ela se restringe ao círculo de uma sociedade que se nutre tão-somente das sombras de seu passado, e que, portanto, não aponta para a sua própria superação.

Como se sabe, a análise freudiana dos sonhos é quase que inteiramente voltada para os sonhos noturnos; são poucos os momentos nos quais Freud se dedica a aclarar a natureza dos sonhos diurnos e, quando o faz, acaba por estender as mesmas leis que regem os sonhos oníricos para os sonhos de vigília. Não obstante, a afirmação de que o sonho é a realização de um desejo também caberia aos sonhos diurnos, na medida em que estes últimos podem realizar, no ato de fantasiar, aquilo que na realidade não seria facilmente praticável. Mas de modo geral, tanto aos sonhos diurnos quanto aos noturnos seriam dadas certas anuências em relação ao princípio de realidade - visto que é este que determina, de modo repressivo, o funcionamento do aparelho psíquico. O princípio de realidade, segundo Freud, ao converter os antigos processos primários (o princípio de prazer) em algo que se adapte melhor à realidade humana, transformou de tal modo o funcionamento do aparelho mental de homens e mulheres que estes renunciaram àquela busca do prazer irrestrito por um prazer sublimado e restritivo, porém garantido e menos destrutivo. $\mathrm{O}$ aspecto traumático que foi o precursor dessa transformação radical surgiu a partir do momento em que homens e mulheres aceitaram a impossibilidade de uma satisfação plena de seus desejos - satisfação essa que poderia levá-los à autodestruição. À fantasia diurna, contudo, ainda seria dada uma maior autonomia em relação à realidade, mas sob o puro aspecto de um gozo mutilado.

No sonho noturno há uma diminuição da excitação corporal, bem como do trabalho psíquico consciente. As sensações exteriores deixam de afetar ou estimular o corpo e, para que o sonhador não desperte, o sono é capaz até mesmo de se proteger do mundo exterior e, para tanto, ele irá integrar para si quaisquer perturbações provindas dos estímulos exteriores (uma batida de porta, por exemplo) e interiores (fome, sede etc.) - cria-se assim o terreno propício para que haja a elaboração onírica, por parte do aparelho psíquico. Freud nos revela que a elaboração onírica não é apenas uma proteção do sono ou uma alucinação despida de qualquer sentido, mas antes, uma "realização fictícia de uma fantasia desejante inconsciente" (BLOCH, 2005, p. 81). Conjuntamente à diminuição dos estímulos há também o enfraquecimento daquele eu censurador: abrese o caminho para que certos conteúdos inconscientes componham a elaboração onírica (ainda que a censura, mesmo enfraquecida, tente dissimulá-los). É preciso lembrar que, para Freud, a elaboração dos conteúdos oníricos e os desejos a eles interligados têm a sua origem na infância, assimilando as emoções e, até mesmo, os mecanismos psíquicos infantis.

Em relação aos sonhos diurnos, Freud colocará em evidência dois momentos: (I) o fantasiar próprio de crianças e de adultos e (II) o fantasiar da criação artística. Em relação à infância, o fantasiar presente nas brincadeiras, devido à importância e ao dispêndio de emoção com que é exercida, possui a capacidade de adaptar o real de acordo com o desejo da própria criança. (Considere-se também o fato de que nessa idade o aparelho psíquico ainda não foi modelado completamente pelo princípio de realidade). Com o avançar da idade cessam as brincadeiras e o amadurecimento exigirá dos indivíduos uma seriedade maior em relação à realidade - os devaneios, ainda que façam parte do cotidiano dos adultos, deixam de ter o fulgor que antes lhes era conferido na infância. A atividade lúdica é substituída pelo trabalho e a característica expansiva das brincadeiras reduzida à introspecção daquele que devaneia. Como sempre, Freud chama a nossa atenção para o fato de que o fantasiar próprio ao adulto, de um modo ou de outro, estaria remetido "à lembrança de uma experiência anterior 
(geralmente na infância) na qual esse desejo foi realizado, criando uma situação referente ao futuro que representa a realização do desejo" (1996a, p. 153). Ademais, o fantasiar na fase madura desembocaria em duas características principais: "ou são desejos ambiciosos, que se destinam a elevar a personalidade do sujeito, ou são desejos eróticos" (1996a, p. 151).

Vejamos o exemplo, dado Freud, de um fantasiar característico da fase adulta neste caso, referido aos desejos ambiciosos. Ele descreve um "pobre órfão" que se dirige a uma firma em busca de emprego e que, a caminho, fantasia que além de conseguir o emprego, conquista as "boas graças" do patrão e sua família, casa-se com a sua "encantadora filha" e, ao final de tudo, torna-se o dono da própria firma. Por fim, o desejo desse sonhador, que se projeta ao futuro, para uma situação ainda não vivida, remeteria ao que este possuiu em algum momento de sua infância. $\mathrm{O}$ desejo do futuro estaria, portanto, atado ao fio do passado. Note-se, de passagem, que ao descrever o desejo do desempregado Freud, em nenhum momento, se referiu às possíveis dificuldades que a falta de trabalho poderia impor ao sujeito, isso porque os desejos mais imediatos (como a fome), interpostos por uma ordem social e econômica desfavorável, não seriam os mais adequados à categoria dos desejos exigidos pela teoria psicanalítica.

No que concerne ao fantasiar da atividade artística, ela permitiria, de maneira sui generis, uma reconciliação entre o princípio de prazer e o princípio de realidade. $\mathrm{O}$ artista, segundo, é aquele sujeito que, por não aceitar a renúncia da satisfação instintual imposta pela realidade, acaba por conceder "a seus desejos eróticos e ambiciosos completa liberdade na vida da fantasia" (1996b, p. 284). Ele obteria através de seu devaneio criador aquilo que desejasse sem "percorrer o longo caminho sinuoso" que a realidade exige para a efetivação de seus desejos - contudo, essa reconciliação entre os dois princípios só se dá no âmbito de uma ficcionalidade.

Em resumo, poderíamos dizer que as fantasias diurnas, tanto nas crianças quanto nos adultos, e até mesmo nos artistas, estão localizados em uma espécie de metarealidade e, justamente por isso, lhes são permitidas algumas anuências para que realizem, ao menos imaginariamente, aquilo que até então permanece impraticável ou inacessível na própria realidade. Mas, de um modo geral, sob o ponto de vista psicanalítico, os sonhos diurnos permanecem, em muitos aspectos, idênticos aos sonhos noturnos: "no fundo, o sonho noturno nada mais é que um sonho diurno que se tornou aproveitável pela liberdade noturna dos movimentos impulsivos, um sonho diurno desfigurado pela forma noturna da atividade psíquica" (FREUD apud BLOCH. 2005, p. 88).

Bloch, por sua vez, irá distinguir essencialmente os sonhos diurnos dos sonhos noturnos. Segundo ele, as leis que regem a elaboração onírica destes estão longe de serem as mesmas que conduzem os sonhos diurnos. O fundamento dessa distinção, grosso modo, se encontra na orientação temporal tanto de um quanto de outro: enquanto os sonhos noturnos geralmente se nutrem da vida impulsiva que ficou para trás, em contrapartida, os sonhos diurnos estão abertos para o futuro. Obviamente, a análise de Bloch necessitará de um exame mais detalhado dos sonhos diurnos, uma vez que estes abrangem desde "o tipo cômodo, trivial, rude, fugaz, despropositado e paralisante, até o tipo responsável, engajado na causa de ações precisas e o tipo modelador da arte" (2005, p. 89). Como observa Furter, "o sonho acordado manifesta uma verdadeira fome psíquica pela qual o homem imagina planos futuros e outras situações em que supere os problemas, as dificuldades e as obrigações de um hoje onipresente" (1974, p. 83). Ademais, são ressaltados pelo filósofo quatro aspectos essenciais dos sonhos diurnos, a saber: (I) o livre curso, (II) o ego preservado, (III) a melhora do mundo e (IV) o desejo 
de ir até o fim.

Segundo Bloch, (I) o eu do sonho acordado é capaz de manipular, criticar e dialogar com as representações mentais, escolhidas segundo a vontade do próprio sonhador. E, caso este não sofra de distúrbios alucinatórios, ele poderá, por mais longe que o devaneio o tenha levado, retornar ao seu presente no momento em que desejar, ao menor aceno - diferentemente do ego do sonho noturno, o qual, em função das leis que regem a elaboração onírica, encontra-se profundamente debilitado. Deste modo, (II) o ego do sonho acordado permanece intacto no contexto de sua vida e de seu mundo. Quando dormimos, os estímulos exteriores são parcialmente eclipsados e o nosso corpo adormece; mas, quando o sonhador encontra-se bem acordado, ele abandona a introversão do sono e estabelece um relacionamento mais imediato com o mundo ao seu redor. Além do mais, enquanto o sonho noturno se fecha sobre si mesmo, exigindo para si a solidão, o eu que fantasia à luz do dia pode reportar-se publicamente, pode ser narrado aos demais - aliás, segundo a recomendação de Bloch, "entusiasmadas conversas com um amigo são especialmente apropriados à prática do sonho desperto" (2005, p. 88). (III) O fato de se manterem abertos ao mundo permite aos sonhos diurnos se projetarem sobre as condições reais, já dadas, a fim de torná-las mais adequadas ao desejo que surge interiormente. Segundo o filósofo, tais "ilusões projetivas" dos sonhos diurnos ainda seriam análogas, mesmo que não patologicamente, às projeções paranoicas: o paranoico reage aos poderes exteriores que lhe interpelam "com queixumes e mania de perseguição", porém, ao seu modo, ele também é capaz de dissipá-los "com invenções aventurescas, receitas sociais, estradas celestiais e muitas coisas semelhantes". É justamente em semelhança a essa capacidade de reação às interpelações e imposições da realidade, que o filósofo salientará o aspecto paranoico "saudável" dos sonhos despertos, uma vez que estes, por meio da projeção utópica, também pretendem, contra os males da realidade, a melhoria do mundo - talvez esse seja o motivo de haverem tantos "loucos" entre os projetistas e "pelo menos alguns entre os grandes utopistas":

Quase toda utopia, seja médica, social ou técnica, possui características paranóicas. Para cada autêntico pioneiro, há centenas de fantasiosos irrealistas, loucos. Se fosse possível pescar as alucinações que nadam na aura dos manicômios, seriam encontradas (...) as prefigurações mais admiráveis da paranóia. E entre estas não se encontra nenhum símbolo noturno latente, (...) e sim novas composições, transformações do mundo, projetos que avançam, em suma, corujas de fogo de uma Minerva louca, mas cheia de vontade de fazer luzir a aurora. (BLOCH, 2005, p. 95)

A arte, que segundo Freud estaria submetida às regras do princípio de realidade, ou seja, tomada apenas enquanto um desvio pulsional socialmente aceito, é vista por Bloch como elemento capaz de subverter os pressupostos dados da realidade: as fantasias artísticas, que são um uma extensão sui generis dos sonhos diurnos, também visariam, de maneira especialmente significativa, a melhoria do mundo. A arte, sob a perspectiva blochiana, é capaz de transbordar os limites da consciência por meio de suas variadas formas e conteúdos: a suo modo ela pode ultrapassar o que até então a realidade não era capaz de pronunciar - ela amplia, em suas texturas, o horizonte de possibilidades da matéria, ou seja, da própria realidade. $\mathrm{Na}$ arte, "os seres humanos e as situações são levados à última consequência em virtude do sonho diurno levado até o fim: o consequente e o objetivamente possível torna-se visível" (BLOCH, 2005, p. 96). (IV) Isso não quer dizer, todavia, que o sonho desperto se deleite em saciar os desejos apenas espiritualmente. Naquele que sonha está implícita a vontade de ir além, uma 
inquietação que anseia levar a cabo o desejo presente nas fantasias, mesmo as mais banais, mas certamente e de modo intenso nas que almejam a melhoria do mundo.

A análise blochiana dos sonhos despertos não se resume apenas a uma diferenciação qualitativa destes com relação aos sonhos noturnos. Quando ele ressalta a natureza antecipatória dos sonhos diurnos - temporalmente voltada para o futuro, para ainda-não-existente - ele lança os pressupostos teóricos para uma reorientação radical do conceito de inconsciente. Em contraposição ao inconsciente que se revela através dos sonhos noturnos, e que pode ser caracterizada como um não-mais-consciente, os sonhos diurnos, segundo filósofo, também revelam em si mesmos um inconsciente de novo tipo, não mais subordinado aos acontecimentos do passado, mas como algo que alvorece a partir do futuro: o ainda-não-consciente. No capítulo XV, de $O$ Princípio Esperança, o filósofo define o ainda-não-consciente como o "pré-consciente do vindouro, o local psíquico de nascimento do novo". Essa nova classe de consciência encontra-se diretamente relacionada a um saber que desponta a partir do futuro, do "completa e inesperadamente novo":

O ainda-não-consciente é de fato tão pré-consciente como o inconsciente da repressão ou do esquecimento. À sua maneira, é um inconsciente tão difícil e renitente como o da repressão. Porém, de forma alguma está subordinado à consciência atual, manifesta, mas a uma consciência futura, que apenas está surgindo. (BLOCH, 2005, p. 117)

Como havíamos sugerido, o inconsciente freudiano, ainda que tenha sido uma grande descoberta, não deixa de ser o reflexo de uma sociedade que se esgota na rememoração de seus traumas. Para romper a cadeia de repetições de um passado indigesto, será preciso contorná-lo com o que ainda-não-veio-a-ser: o que o sujeito deve buscar "não é bafio de porão, mas o ar da manhã" (BLOCH, 2005, p. 117). Antes de partirmos para uma análise detalhada de como se dá a produção e a elaboração dos conteúdos ainda-não-conscientes, é interessante destacar as analogias feitas pelo filósofo para esboçar as características gerais dessa nova classe de consciência, através das noções de juventude e mudanças de época.

Recorrentemente, Bloch faz alusões aos aspectos sociológicos e psicológicos que envolvem a juventude. Os "anos verdes" são caracterizados pelo filósofo - não sem uma dose de romantismo revolucionário - como sendo um período de mudança, um locus transitório em que ressoam as vozes do "ser-diferente, do ser-melhor, do ser-maisbelo". A vida nesse estágio ainda reflete o amanhã, sonha com a viagem intrépida pelo oceano do futuro, com a abertura dos anos que ainda consistem em estados não conscientes. "A boa juventude", diz-nos o filósofo, "sempre vai atrás das melodias do seu sonhar e de seus livros, espera encontrá-las, conhece a errância ardente e obscura pelo campo e pela cidade, aguarda a liberdade que lhe está adiante" (BLOCH, 2005, 118). Todavia, o interesse do filósofo em relação a esse estágio da vida humana não se resume, apenas, à ordem descritivo-antropológica. Na investigação sobre o ainda-nãoconsciente, a "juventude" servirá para definir os parâmetros de uma consciência que se comporta de modo ativo, que procura sair de sua própria imaturidade para estabelecer e engendrar novos parâmetros de vida. A noção mesma de juventude, nesse sentido, encontra-se estreitamente relacionada à outra noção, a de mudanças de época:

As próprias épocas de mudança são os períodos de juventude na história, isto é, estão objetivamente diante dos portões de uma nova sociedade em ascensão, assim como a juventude se sente subjetivamente diante do limiar de um dia de vida que até aquele momento ainda não havia sido inaugurado. (BLOCH, 2005, 118-119) 
As épocas de mudança manifestam, deste modo, o ímpeto que é próprio da juventude num plano mais geral, isto é, histórico, ideológico e cultural. Um modelo exemplar dessas "primaveras históricas" se deu na guinada dos séculos XV e XVI. É justamente nesse intervalo que se inicia a marcha das utopias. Também a reforma protestante desencadeou, em locais específicos da Europa, a possibilidade de uma nova configuração para as relações sociais e materiais - o que desmantelaria, em parte, o poder exercido pela Igreja católica, abrindo o caminho necessário para que o gérmen do mercantilismo e do liberalismo econômico fossem desenvolvidos. A ciência moderna, por sua vez, foi capaz de romper a abóboda celeste e liberar "a vista para o infinito". Ao mesmo tempo, o Renascimento trazia consigo as bases do humanismo, através da busca de um novo homem, o início de uma nova vida - Incipit vita nova. Tudo isso manifestava, segundo Bloch:

Um pré-consciente muito poderoso, que alargou o espaço e foi além das colunas de Hércules estabelecidas até aquele momento. Iniciou-se uma renovação total da arte, da vida, da ciência (...). No ar dessas primaveras históricas vibram planos em busca de execução, idéias em incubação. Jamais os atos prospectivos foram mais numerosos e mais comuns do que então, jamais o antecipatório nelas foi mais pleno de conteúdo, jamais a sintonia com o que vem chegando foi mais irresistível. (BLOCH, 2005, p. 119).

Em geral, as noções de juventude e mudanças de época servem não apenas enquanto recursos metafóricos, mas também para designar as características gerais que sobrevoam os períodos de rupturas na história, aqueles momentos que foram capazes de superar e "sacudir sistemas sociais com suas estruturas caducas" (cf. MÜNSTER, 1997, p. 28 e ss). Esses períodos, afirma o filósofo, estão sobrecarregados com conteúdos ainda-não-conscientes. De qualquer modo, para além das conotações gerais que envolvem o ainda-não-consciente, faz-se necessária uma apreciação mais específica em relação ao surgimento do novum, ele mesmo. Para tanto, Bloch traça um plano fenomenológico dos aspectos psicológicos que abarcam a produção criativa, e que se subdivide em três momentos específicos: a incubação, a inspiração e a explicação. Vejamos.

A incubação, segundo o filósofo, é o momento que antecede a descoberta do novo, é o prelúdio da criação do que ainda não encontrou o seu enunciado definitivo. É um estado, em certa medida, incômodo, no qual "ocorre um opinar veemente, que tem em mira o que se está buscando, o que está vindo como alvorecer"; a incubação surge como "um nevoeiro psíquico", "um estágio de escuridão, mas com forte propensão a se dissipar" (BLOCH, 2005, p. 122). Podemos encontrar vestígios semelhantes a esse estado mental na gravura Melancolia I, de Albrecht Dürer. Nela, o anjo representado toma a feição de um pensador ensimesmado, e o seu aspecto introspectivo pode ser comparado ao mesmo estado lacônico de uma consciência que se esgota numa concentração extrema, na tentativa de resolver e se libertar do peso que antecede a descoberta. A incubação, em todo caso, pertence àqueles três quartos de hora que antecedem a aurora - ela, geralmente, é precedida por uma iluminação súbita, a inspiração:

A incubação, que parecia não ter voz, às vezes podendo provocar um tipo de vazio da consciência por causa de alguma sobrecarga, já não é mais lacônica. (...) A solução surge repentinamente, parecendo tão imediata, ou seja, sem consciência do longo período de incubação, que a inspiração facilmente traz consigo, ou melhor, trouxe consigo a sensação milagrosa do presente mágico, ao lado da sensação feliz de libertação. (BLOCH, 2005, p. 123) 
Não devemos, contudo, entender a inspiração como um lampejo divino, algo que, luminosamente, despencaria sobre nós, de cima para baixo. Em conformidade com o que temos dito até agora, esse segundo momento da produção criativa deve ser compreendido como uma espécie de coincidência entre "uma predisposição específica e genial, isto é, criativa, com a predisposição de uma época para propiciar o conteúdo específico, cuja expressão se tornou madura para ser enunciada" (BLOCH, 2005, p. 124). Portanto, o surgimento do novum, desencadeado pelo espanto da inspiração, dependerá do encontro, muitas vezes fortuito, das condições subjetivas de enunciação e das possibilidades reais latentes no âmago da objetividade: a inspiração é o encontro entre a demanda criativa e a tendência objetiva da época, "ela é a centelha que acende essa concordância". Um exemplo disso, diz-nos Bloch, ocorreu com Descartes, quando da descoberta do cogito: "sem a demanda capitalista, a demanda subjetiva do cogito ergo sum nunca teria encontrado a sua inspiração" (BLOCH, 2005, p. 124).

Por fim, será por meio da terceira e última fase da produção criativa, a explicação, que os momentos anteriores (incubação e inspiração) alcançarão uma linguagem efetiva, abrangente, fazendo com que o ainda-não-consciente seja abarcado pela realidade objetiva. Não obstante, prossegue o filósofo, a explicação é o estágio mais "doloroso e trabalhoso" da produção criativa, pois é o momento em que deve ser articulada a configuração do novum, o momento de engendrá-lo em fórmulas, conceitos, cores, gestos, sons etc. Em poucas palavras, a explicação é o ato de dizer o que até então permanecia inefável, indizível. De um modo geral, o aparecimento do novum dependerá do afloramento de uma "sensibilidade extrema" - extrema no sentido de que é capaz de perceber o movimento latente da realidade e, acima de tudo, é capaz de plasmá-lo em sua imanência. A produção genial, nesse sentido, aparece como um momento privilegiado na mediação entre as tendências materiais e as potencialidades subjetivas, em vistas do surgimento do novo. ${ }^{1}$ Em Das Materialismusproblem (1972), Bloch define a atividade criadora do gênio como sendo um plus ideológico, ou seja, como algo que vai além da mera determinação cultural, já estabelecida por uma época. Sob essa perspectiva, tal atividade torna-se, par excellence, utópica:

Assim, a grande arte ou a grande filosofia não é a mera manifestação de seu tempo em imagens e ideias, mas sim a jornada de seu tempo e as perspectivas de seu tempo, caso haja alguma, manifestada em imagens e ideias. (...) A obra do gênio produz mais que uma simples projeção, e suas figuras e situações, elas mesmas - sobretudo nas produções estéticas - dão expressão às linhas essenciais de uma extensão que faz parte de sua força motriz. (BLOCH, 1998, p. 38-39).

O gênio é aquele que é capaz de cumprir o que se porta como "objetivamente necessário numa determinada esfera", justamente por transitar em conteúdos que concordam tanto com as tendências materiais quanto com as tendências históricosociais de sua época. De acordo com Bloch, a atitude genial "não é, como o talento, grande por sua versatilidade formal, embora possa possuí-la", mas grande por cumprir, através de seu destino individual, a tendência e a latência implícitas na própria matéria dialética: "ele deve se projetar além de tudo o que está dado e elaborar como uma satisfação pessoal aquilo que objetivamente acompanha o curso de sua época". (ROSENKRANZ apud BLOCH, 2005, p. 125). (Isso não quer dizer que essa nova classe de consciência esteja restringida, unicamente, à produção criativa genial - ainda que neste caso o novum possa ser desenvolvido e explicado de modo excepcional).

Em resumo, até aqui tentamos realçar qual intenção Bloch ao propor romper a rigidez do paradigma freudiano fundado sobre o não-mais-consciente. Dos sonhos diurnos ao surgimento do ainda-não-consciente, a filosofia blochiana sobreleva a 
importância do futuro na tentativa de estabelecer um novo paradigma epistemológico e psicológico. Todavia, apesar de termos quase sempre enfatizado a especificidade de uma filosofia que se pretende prospectiva, diretamente relacionadas ao devir histórico, falta-nos demonstrar como o pensamento blochiano se relaciona com os conteúdos do passado. Isso não quer dizer, contudo, que tenhamos de dar um giro abrupto em nossa análise, ou mesmo adentrando em um campo de análise que nos levaria à contradição. A descoberta do ainda-não-consciente também dependerá de interação constante com os conteúdos históricos, pois o surgimento do novum, em sentido mais amplo, devido à resistências contextuais e mesmo materiais, acontecerá de modo fragmentário:

Nem todas as noções e obras são possíveis em todos os tempos. (...) As [obras] que transcendem a sua época são concretamente irrealizáveis, mesmo quando excepcionalmente, podem ser apresentadas de modo abstrato. Mas essa barreira também está fundada, em última instância, unicamente na condição histórica do material, sobretudo no estado processual e inacabado que lhe é próprio e no qual ele mesmo se encontra, ou seja, em forma de esboço, de front e de fragmentos. Esse também é o caso quando há apenas fragmentos de um novo conhecimento e não o conhecimento de algo objetivamente novo. (BLOCH, 2005, p. 130).

A passagem supracitada é importante para uma compreensão exata das determinações que sobrevoam o surgimento de conteúdos ainda-não-conscientes. Em primeiro lugar, é preciso compreender que o surgimento do novum, certas vezes, dependerá das condições oferecidas objetivamente, ou seja, das possibilidades reais, tanto no que respeita à superação das determinações socioeconômicas quanto àquelas interpostas pela própria matéria. Destarte, uma vez que a matéria se encontra em processo, o surgimento do novum também se dará de forma processual. É justamente nesta medida que a volta aos conteúdos do passado pode contribuir, de modo essencial, para o avanço da consciência antecipatória, pois a história humana guarda em si conteúdos que ainda permanecem vivos, não desdobrados em sua totalidade e que permanecem enquanto fragmentos de um novo conhecimento, que ainda não se manifestou completamente, que não se tornou algo objetivamente novo.

$\mathrm{O}$ ainda-não-consciente, como vimos anteriormente, tem como substrato os sonhos diurnos, os signos refletidos de um não-aí, por meio dos quais os indivíduos elaboram as suas faltas, suas necessidades, seus anseios ainda não realizados. Não devemos esquecer que o ainda-não-consciente se constitui enquanto uma extensão essencial da consciência antecipadora que, por seu turno, deve ser compreendida como toda e qualquer manifestação refletida (afetos expectantes positivos) cujo intento é o de romper a obscuridade do momento vivido, isto é, o desejo de ir-além da realidade imperfeita. E o que orientará positivamente essa nova classe de consciência é o ímpeto provido pela docta spes, ou seja, a esperança refletida, mediada de modo antecipatório e que não visa outra coisa senão o futuro autêntico - em oposição ao inautêntico, em que nada de novo acontece. O ato "consciente-ciente" do projetar antecipatório, quando interpolado com a esperança, dá forma ao que Bloch denominou de função utópica da consciência, isto é: uma intenção expectante "que supera o meramente existente em sua dialética material".(BLOCH, 2005, p. 144). É a função utópica, por seu turno, que irá distinguir o mero fantasiar (wishful thinking) do fantasiar utópico-concreto e revolucionário, que busca pelo novum:

(...) o conteúdo ativo da esperança, na qualidade de conscientemente esclarecido, cientemente explicado, é a função utópica positiva, enquanto conteúdo histórico da esperança, evocado primeiro em representações, investigando enciclopedicamente em juízos concretos, é a cultura humana na relação com o 
seu horizonte utópico-concreto. É nessa noção que trabalha a combinação docta spes, como afeto expectante na ratio, como ratio no afeto expectante.

E, uma vez que os conteúdos expectantes participam ativamente no avançar do processo histórico, na elaboração da matéria utópica, a história da cultura humana está constituída por um conjunto de sedimentos ou fragmentos que abrigam diretamente a função utópica, ou seja, a manifestação de conteúdos que, apesar de não realizados em sua totalidade, indicam o caminho para surgimento do novum. Em outras palavras, isso significa que a história da humanidade carrega em si o registro de inúmeras manifestações, uma herança cultural que reflete a jornada na busca pelo ainda-nãorealizado e que, em última instância, converge na busca pela emancipação. ${ }^{2}$ Destarte, o filósofo concorda em grande parte com o projeto filosófico benjaminiano. Em suas Teses sobre o conceito de história, Walter Benjamin nos diz que a empreitada do teórico formado na escola do materialismo dialético é a de fazer explodir o continuum da história - de ser capaz de perceber seu objeto histórico, aquele cheio de tensões, enquanto paragem messiânica do devir. Do mesmo modo, Bloch também distingue a filosofia de Marx como aquela que "conhece todo o passado em sua amplitude criativa", justamente porque "não conhece nenhum outro passado a não ser o ainda vivo", e completa: "a filosofia de Marx conhece igualmente o passado em sua amplitude criativa, porque ela não conhece nenhum outro passado a não ser o ainda vivo, o ainda não liquidado" e "o passado vingado, herdado, mediado e plenificado torna-se visível no futuro" (BLOCH, 2005, p. 19).

\section{REFERÊNCIAS BIBLIOGRÁFICAS}

BICCA, L. Marxismo e Liberdade. Trad. Vânia Sampaio. São Paulo: Loyola, 1987.

BLOCH, E.. O Princípio Esperança. Volume I. Trad. Nélio Schneider e Werner Fuschs. São Paulo: Contraponto Editora, 2005.

BLOCH, E. The Utopian Function of Art and Literature. Trad. Jack Zipes e Frank Mecklenburg. Cambridge: The MIT Press, 1998.

MASCARO, A. Utopia e direito - Ernst Bloch e a ontologia jurídica da utopia. São Paulo: Quartier Latin,. 2008.

MÜNSTER, A. Utopia, messianismo e apocalipse nas primeiras obras de Ernst Bloch. Trad. Flávio B. Siebeneichler. São Paulo: Ed. Unesp, 1997.

MÜNSTER, A. Escritores criativos e devaneios. In: Obras Standard, volume IX. Rio de Janeiro: Imago, 1996a.

MÜNSTER, A. Formulações sobre os dois principios de funcionamento mental. In: Obras Standard, volume XII. Rio de Janeiro: Imago, 1996b.

FURTER, P. Dialética da esperança. Rio de Janeiro: Paz e Terra, 1974.

GEOGHEGAN, V. Ernst Bloch. London: Routledge, 1996.

\section{Notas}

1 "Gênio é, portanto, o cruzamento explosivo da capacidade subjetiva com a tendência objetiva". (Cf. GEOGHEGAN, 1996, p. 48 e ss).

2 A genialidade de Bloch é a de lançar mão, para a concretização da ação política, de heranças culturais, ideologias, espirituais e morais que são a linha de frente da dialética contemporânea, isto porque, a história para Bloch, é um somatório contraditório de demandas não resolvidas, cujas energias se acumulam e não se canalizam em apenas uma frente de transformação. (MASCARO, 2008, p. 185) 